\title{
SISTEMA DE INFORMAÇÕES GEOGRÁFICAS E CADASTRO DE ESTABELECIMENTOS COMERCIAIS URBANOS DE UM PEQUENO MUNICÍPIO DO ESTUÁRIO DO RIO AMAZONAS
}

\section{GEOGRAPHIC INFORMATION SYSTEM AND CADASTRE OF URBAN COMMERCIAL ESTABLISHMENTS OF A SMALL MUNICIPALITY IN THE AMAZON RIVER ESTUARINE REGION}

\author{
Pedro Henrique Issa ${ }^{1}$ \\ Jéssica Andretta Mendes ${ }^{2}$ \\ Viviana Mendes Lima ${ }^{3}$ \\ Sandra Maria Fonseca da Costa ${ }^{4}$
}

RESUMO: Este artigo tem como objetivo apresentar a utilização de técnicas de geoprocessamento como ferramenta para mapear os pontos comerciais urbanos do pequeno município de Ponta de Pedras, localizado na Illha do Marajó, Pará, como subsídio ao cadastro urbano. Sabe-se que o geoprocessamento é uma importante ferramenta para os tomadores de decisão, no sentido de compreenderem o espaço geográfico e a distribuição e crescimento de seus atributos, temporalmente. No caso apresentado neste artigo, foi possível localizar os estabelecimentos comerciais urbanos e suas características, em termos de atividade, do município de Ponta de Pedras, utilizando-se um GPS e elaborar um mapa com estas informações. Esse município tem baixa arrecadação de impostos e, basicamente, depende dos repasses da união, o que torna difícil o investimento municipal em mapeamentos que possam subsidiar as políticas públicas. É nesse sentido que este trabalho se estrutura, com a finalidade de auxiliar na produção de um cadastro comercial urbano inicial, possibilitando a criação de um banco de dados, utilizando o SIG (Sistema de Informações Geográficas) como ferramenta.

Palavras-chave: estabelecimentos comerciais; geoprocessamento; banco de dados.

ABSTRACT: This paper utilizes geoprocessing techniques to map urban commercial establishments in the municipality of Ponta de Pedras, located on Marajó Island, Pará, as an aid to urban cadastre. Geoprocessing provides important tools for decision makers to understand geographical space and the spatial distribution as well as temporal evolution of its components. In this case study, this tool made it possible to locate urban commercial establishments and characterize them, using GPS and fieldwork observation. Then a map was elaborated with this information. The municipality of Ponta de Pedras has low tax income, and it strongly depends on the Union financial resource transferences, which makes it difficult to invest in mapping activities that are important to support public policies. Therefore, this paper was structured with the aim of elaborating a preliminary urban commercial cadastre based on a spatial database using GIS (Geographic Information System) as a tool.

Keywords: locate commercial; geoprocessing; system; database.

\footnotetext{
${ }_{1}^{1}$ Graduando em Geografia - Universidade do Vale do Paraíba - Univap. E-mail: pedro.ansatsu@hotmail.com.

${ }^{2}$ Graduanda em Geografia - Univap e bolsista de Iniciação Científica da FAPESP. E-mail: jessy1990@ig.com.br.

${ }^{3}$ Mestre em Planejamento Urbano e Regional - Univap e Professora . E-mail: geolimabrasilch@yahoo.com.br.

${ }^{4}$ Doutora em Informação Espacial pela Universidade de São Paulo - USP e Pró-reitora de Pesquisa e Pós-graduação Stricto Sensu da Univap. E-mail: sandra@univap.br.
} 


\section{INTRODUÇÃO}

Sistema de Informações Geográficas (SIG) refere-se àqueles sistemas que efetuam tratamento computacional de dados geográficos e permite ao analista fazer uma melhor análise dos dados. Usualmente, por meio da utilização de SIG, pôde-se espacializar informações coletadas em campo, armazenando a geometria e os atributos dos dados que estão georreferenciados, isto é, localizado na superfície terrestre e em uma determinada projeção cartográfica (CÂMARA, 1998). Assim, um SIG é um conjunto de ferramentas para coletar, armazenar, recuperar, transformar e visualizar dados sobre o mundo real (BURROUGH, 1998).

O SIG pode ser utilizado de diversas formas, porém as principais formas de utilização são: como ferramenta para produção de mapas, possivelmente a maneira mais utilizada; como suporte para análise espacial de fenômenos; e como um banco de dados geográficos, com funções de armazenamento e recuperação da informação espacial (CÂMARA, 1998). A sua utilização vem influenciando, de maneira crescente, as áreas de Cartografia, Geografia, Análise de Recursos Naturais, Transportes, Comunicações, Energia e Planejamento Urbano e Regional.

Burrough (1998) considera que a demanda por mapas de topografia e temas específicos da superfície da Terra, assim como de recursos naturais, aumentou no século XX, por diversas razões. Além da utilização militar, há, também, o interesse dos países por mapear e monitorar suas riquezas naturais, bem como as dos seus vizinhos. Um Exemplo desse mapeamento são os inúmeros mapas e imagens referentes ao desmatamento da Amazônia (INSTITUTO NACIONAL DE PESQUISAS ESPACIAIS, 2011) pelo Governo Brasileiro. Outras variáveis, tais como informações sociais, econômicas, de saúde, de territorialidade, e de uso do solo, também são muito utilizadas, pelos órgãos públicos e privados, e, dessa maneira, permitem acompanhar as transformações que ocorrem no espaço geográfico. Nesse sentido, a elaboração de mapas não é a única função de um SIG, mas uma das mais utilizadas.

De acordo com Di Maio (2011), um mapa é "a representação de um espaço real, transmitida em linguagem cartográfica que se utiliza de 3 elementos básicos: sistema de signos, redução e projeção". Para a autora, entender mapas significa dominar essa linguagem cartográfica. A autora ainda discute que, na cartografia, há mapas topográficos e temáticos. Os mapas topográficos apresentam os detalhes planialtimétricos (aspectos naturais e artificiais de uma área), o que permite a determinação de altitudes por intermédio de curvas de nível. Os mapas temáticos são documentos cartográficos, em quaisquer escalas, que representam os fenômenos geográficos, por temas (uso do solo, p.e.) e transmitem informações sobre determinada grandeza, de forma a diferenciar os valores e demonstrar, visualmente, suas discrepâncias.

Um mapa cadastral não pode ser considerado um mapa temático ou mesmo planialtimétrico, de fato. De acordo com Câmara e Medeiros (1996), "é aquele em que cada um dos seus elementos é um objeto geográfico, que possui atributos e pode estar associado a várias representações gráficas. Por exemplo, lotes em uma cidade são elementos do espaço 
geográfico que possuem atributos não espaciais (localização, valor venal etc.) e podem ter representações gráficas diferentes em mapas de escalas distintas". Ou seja, a função básica é produzir um banco de dados (com atributos) de um local, associado a elementos espaciais (pontos, polígonos ou linhas, cuja finalidade é o cadastro urbano.

Em sua pesquisa, Teixeira e Karsburg (2011, p. 7) consideram que o objetivo do cadastro urbano é: coletar as informações descritivas, ou seja, todos os elementos que caracterizam a área urbana; atualizar o sistema descritivo e o conjunto de informações que diferenciam cada propriedade imobiliária; obter um sistema cartográfico georeferenciado e atualizado, sistematicamente; interligar as informações cartográficas e descritivas de maneira que se possa obter cruzamento de informações.

Nesse sentido, o objetivo deste artigo é apresentar uma aplicação da utilização de um SIG na elaboração de um mapeamento de estabelecimentos comerciais urbanos de um município pequeno da Amazônia. Esse mapeamento não pode ser caracterizado como cadastral, mas como uma base para um futuro cadastro urbano de estabelecimentos comerciais. Optou-se por trabalhar com um município pequeno, pois, usualmente, esses municípios têm carência de informações cartográficas, inclusive de recursos públicos destinados aos levantamentos de dados. Nesse sentido, uma questão se faz premente: o que é um município pequeno ou, mais especificamente, uma cidade pequena na Amazônia?

Para o Professor José Aldemir Oliveira (2004), não há uma definição única do que é município ou cidade pequena. O critério primeiro ainda é o demográfico (com menos de 50 mil habitantes), além da baixa articulação com cidades/municípios do entorno, atividades econômicas quase inexistentes, com predomínio do serviço público, baixa capacidade de oferta de serviços básicos (p.e., saúde e educação), predominância de atividades caracterizadas como rurais. De acordo com Costa et al. (2011), as pequenas cidades, sob o ponto de vista populacional, são predominantes na Região Amazônica. No Censo de 2010, as cidades com menos de 20 mil habitantes representavam $64 \%$ de um total de 760 cidades-sede existentes na Amazônia Legal. Neste artigo, consideramos a discussão do Professor José Aldemir como norteadora do conceito de cidade pequena da Amazônia.

O município estudado é Ponta de Pedras, localizado no estado do Pará, o qual possuía, em 2010, 25.999 habitantes (INSTITUTO BRASILEIRO DE GEOGRAFIA E ESTATÍSTICA, 2011), sendo que $47 \%$ de seus moradores vivem na cidade sede. Não há mapas disponíveis, no município, para consulta pública. Considerando esses aspectos, optou-se por apresentar uma proposta de mapeamento de alguns dos estabelecimentos comerciais, de forma a elaborar um banco de dados que possa ser útil ao Poder Público Municipal.

Para esta pesquisa, a utilização do geoprocessamento como ferramenta de suporte possibilitou a criação de um mapa urbano e de um banco de dados básico sobre os estabelecimentos comerciais, apresentando as diferentes tipologias desses estabelecimentos. Essas informações foram especializadas e, utilizando-se dos dados adquiridos em pesquisa de campo, associados a outras informações sociais e econômicas, foi possível produzir mapas que podem auxiliar 
na elaboração de projetos de ordenamento da cidade e na compreensão da dinâmica comercial urbana.

\section{O MUNICÍPIO DE PONTA DE PEDRAS}

O município de Ponta de Pedras localiza-se no estado do Pará, e encontra-se a uma distância, em linha reta, de quarenta quilômetros, aproximadamente, da capital do estado, Belém. O município faz parte da llha do Marajó, na região estuarina do Rio Amazonas. Na Fig. 1, pode-se observar a localização do município.

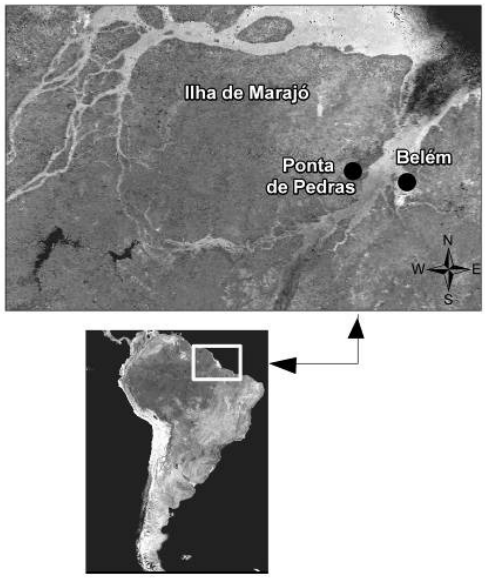

(a)

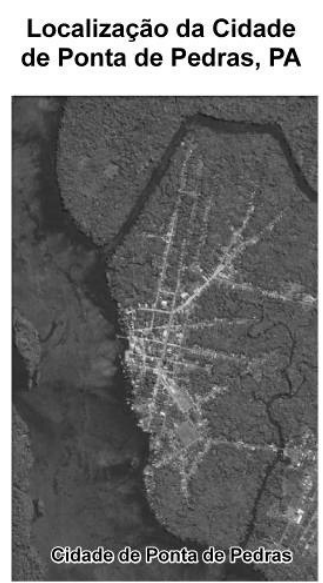

(b)

Fig. 1 - Localização do município de Ponta de Pedras (a) e da cidade (b). Fonte: COSTA et al. (2011).

O meio de transporte mais utilizado para se ter acesso ao município é o barco, que leva cerca de três horas e meia para chegar na cidade de Belém. O açaí é sua principal "identidade econômica" e motor da economia, sendo o município de Ponta de Pedras o segundo maior produtor de açaí do Brasil (INSTITUTO BRASILEIRO DE GEOGRAFIA E ESTATÍSTICA, 2011). A cidade atua como um entreposto de comércio para comunidades vizinhas, mais afastadas da capital.

Em 1920, quando possuía 6.683 habitantes, o município de Ponta de Pedras vivenciou o auge e a falência da atividade extrativista da borracha. Substituída pela economia bovina, em 1940, houve um crescimento da população de, aproximadamente, $72 \%$, sendo esta, nesse momento, predominantemente, rural, a qual representava $89 \%$ da população total. Essa população flutuou entre 10 e 15 mil habitantes, até 1970, de acordo com o IBGE (2011). Costa e Brondízio (2011) afirmam que "com o surgimento da economia do açaí, em meados dos anos 1970, o município apresentou um crescimento urbano e uma crescente migração proveniente de Belém". No Censo de 2010 (INSTITUTO BRASILEIRO DE GEOGRAFIA E ESTATÍSTICA, 2011), o município 
apresentava uma população de 25.999, sendo que $52 \%$ da população ainda residem nas comunidades rurais.

Ao contrário da tendência regional, em Ponta de Pedras houve um crescimento da população rural, e, ao mesmo tempo, não houve desmatamento apesar da expansão de produção motivada pela dinâmica da economia regional do açaí. Entretanto, a produção do açaí passou a ser desenvolvida como uma atividade agrícola, não mais uma atividade extrativista" (BRONDÍZIO, 2008). Mesmo apresentando uma população rural maior do que a urbana, a cidade tem crescido, em termos populacionais e em área.

Em mapeamento realizado, utilizando fotografias aéreas e imagens de satélite, Costa, Brondizio e Montoia (2009) quantificaram o crescimento da área urbana, entre 1969 e 2010. Em 1969, a cidade ocupava uma área de $0,3 \mathrm{~km}^{2}$, apresentando uma expansão de $0,89 \mathrm{~km}^{2}$, nesse período, significando um acréscimo de $248 \%$, como reflexo do aumento populacional verificado no período. Entre 1970 e 2010, houve um crescimento de 9.367 habitantes na área urbana.

Em trabalho de campo realizado à cidade de Ponta de Pedras, nos anos de 2007, 2009, 2010 e $2011^{1}$, no mês de julho, notou-se que houve um crescimento do comércio de forma significativa, com a instalação de estabelecimentos de maior porte. Por exemplo, em 2007, existia apenas um supermercado; em 2011, existiam cinco supermercados, os quais atendiam tanto aos consumidores de maior poder aquisitivo, que

\footnotetext{
1 Os trabalhos de campo realizados em 2007, 2009 e 2010 não se relacionam aos levantamentos de dados mencionados neste artigo, mas ao projeto ao qual este trabalho se relaciona.
}

têm a opção de consumir em Ponta de Pedras ou em Belém, quanto aos de baixa renda que antes encontravam limitação em relação ao transporte para a capital. Esse comércio também atende aos moradores das comunidades ribeirinhas que se beneficiam dessas atividades.

Há uma preocupação, em relação a esse crescimento comercial, associada ao crescimento urbano, por não haver um planejamento adequado, no que diz respeito à localização desses estabelecimentos e nem arrecadação de impostos por parte da Secretaria de Finanças do Município. Há várias "vendinhas" de açaí, que compõem a paisagem comercial da cidade, as quais movimentam a economia local, sendo que muitas não são regularizadas. A Prefeitura Municipal desconhece a localização desses estabelecimentos e a sua expansão. Considerando esse aspecto, esta pesquisa pretende contribuir para a compreensão da distribuição dos estabelecimentos comerciais de Ponta de Pedras, no sentido de propiciar uma análise da situação desses estabelecimentos na cidade e suas características, possibilitando aos gestores exercer o controle e monitoramento dessa atividade.

\section{MATERIAIS E MÉTODOS}

Para a realização desta pesquisa, foram seguidos os passos metodológicos, descritos a seguir:

- em trabalho de campo, realizado entre os dias 24 a 31 de julho de 2011, utilizando-se um GPS (Ground Positioning System), marca Garmim, modelo GPSmap 60CSx, foram coletadas as coordenadas geográficas dos estabelecimentos 
comerciais $^{2}$, localizados no perímetro urbano de Ponta de Pedras;

- posteriormente, os estabelecimentos foram classificados por ramo de atividade, por exemplo: mercados, farmácias, comércios de açaí, entre outros.

- essas informações foram tabuladas no Excel $\AA^{\circledR}$, organizadas segundo o ramo de atividade, endereço e coordenadas UTM (X e Y);

- com essas informações, foi possível converter o modelo do arquivo-texto para o software ArcMap ${ }^{\mathrm{TM}}$, versão 9.2. Esse software é um Sistema de Informação Geográfica (SIG), o qual permite que dados, com localização geográfica (coordenadas espaciais conhecidas), sejam mapeados;

- no $\operatorname{ArcMap}^{\mathrm{TM}}$, procedeu-se ao mapeamento, 0 qual consistiu em espacializar os dados obtidos em campo, e tabulados no Excel $\AA^{\circledR}$, sobre uma imagem QuickBird-2 da cidade de Ponta de Pedras. Essa imagem é uma composição colorida do sensor multiespectral que está a bordo do satélite, de altíssima resolução espacial, obtida em 2009 e possui uma resolução espacial de $2,4 \times 2,4 \mathrm{~m}$, propiciando ao usuário a visualização de detalhes do terreno. No caso desta pesquisa, a imagem foi exportada do Google Earth ${ }^{\mathrm{TM}}$, no formato TIFF (Tagged Image File Format) e, utilizando as ferramentas do Arc-Map ${ }^{\mathrm{TM}}$, a imagem foi georreferenciada (corrigida,

2 O conceito utilizado nesta pesquisa, para que um estabelecimento seja classificado como comercial atende às seguintes condições: o estabelecimento tem que ser utilizado única e exclusivamente para a realização do comércio, o que já exclui estabelecimentos usados tanto como comércio quanto para moradia; o estabelecimento deve estar em funcionamento ou em condições mínimas aparentes de funcionamento, o que também elimina estabelecimentos que não demonstram condições mínimas de atendimento. geometricamente, para o sistema cartográfico UTM-WGS84, mesma projeção dos pontos coletados), possibilitando o mapeamento de 227 estabelecimentos comerciais, distribuídos em 15 ruas da cidade;

- utilizando-se do mapa dos setores censitários (Fig. 2), foi realizada uma análise sobre a distribuição dos estabelecimentos comerciais, de acordo com dados socioeconômicos. Os setores censitários são utilizados pelo IBGE para agregar os resultados do censo, a fim de facilitar as análises dos dados. No caso desta pesquisa, a qual se insere a um projeto maior sobre a cidade de Ponta de Pedras ${ }^{3}$, a utilização dessa base espacial possibilita comparar esses resultados com outros levantamentos, já realizados pelo projeto.

\section{RESULTADOS E DISCUSSÕES}

\subsection{O Banco de Dados Elaborado}

De acordo com os objetivos propostos, foi estruturado um banco de dados, o qual contém os dados dos comércios, mapeados apenas em relação à localização geográfica, em coordenadas UTM (Fig. 3). De acordo com os procedimentos adotados, as coordenadas, de cada estabelecimento, coletadas in locu, com GPS, originaram um mapa de pontos, os quais representam a localização geográfica desses estabelecimentos. A cada ponto foram associados alguns atributos, tais como a tipologia comercial, localização $\mathrm{X} / \mathrm{Y}$,

${ }^{3} \mathrm{O}$ projeto citado intitula-se "A importância das pequenas cidades na rede urbana da Amazônia: crescimento urbano, infraestrutura e políticas públicas", o qual foi aprovado pela FAPESP, processo $n^{\circ}$. 2009/08613-6, coordenado pela Doutora Sandra Maria Fonseca da Costa. 
endereço ${ }^{4}$ e fotografia do imóvel, capturada durante o trabalho de campo.

${ }^{4}$ Em Ponta de Pedras os imóveis, residenciais ou comerciais, não possuem endereço completo, ou seja, os logradouros não possuem numeração. De acordo com informações levantadas em campo, entregas de correspondência ocorrem, pois os carteiros conhecem os moradores.

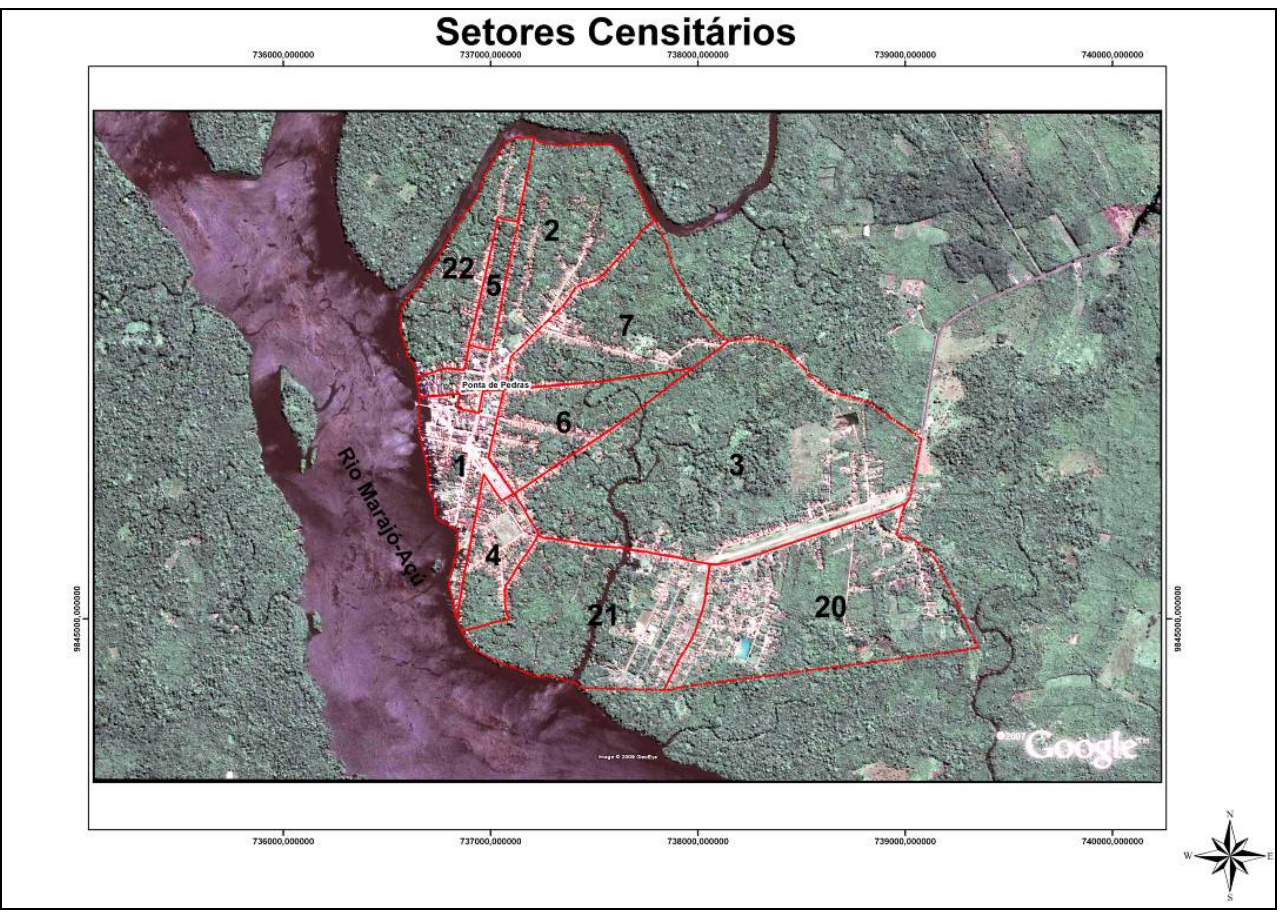

Fig. 2 - Mapa dos setores censitários da cidade de Ponta de Pedras. Fonte: Elaboração própria, utilizando as informações do Censo 2010 (INSTITUTO BRASILEIRO DE GEOGRAFIA E ESTATÍSTICA, 2011).

Como mencionado, não podemos caracterizar este mapeamento como cadastro urbano, pois não foram mapeados os limites territoriais dos estabelecimentos, apenas as suas posições geográficas. Entretanto, na Fig. 3 pode ser observado que 0 banco de dados, elaborado no ArcMap $^{\mathrm{TM}}$, pode originar mapeamentos mais completos e dar subsídios ao poder público, para elaborar um cadastro urbano.

A Tabela 1 apresenta, sinteticamente, o número de estabelecimentos comerciais mapeados. Foram mapeados 227 estabelecimentos comerciais. Observa-se que há uma concentração de estabelecimentos comerciais voltados à venda de roupas e de mantimentos. Essa discussão é detalhada no subitem 4.2. Ressalta-se que, neste artigo, os resultados apresentados são preliminares e que análises mais detalhadas serão desenvolvidas futuramente.

\subsection{Resultados do Mapeamento}

A Fig. 4 apresenta um mapa elaborado por meio dos dados obtidos em trabalho de campo. Esse mapa representa somente os 
comércios de Açaí, nele é possível perceber importante do comércio local, e principal a distribuição espacial desse tipo de fonte de alimentação da população. comércio na cidade, produto mais

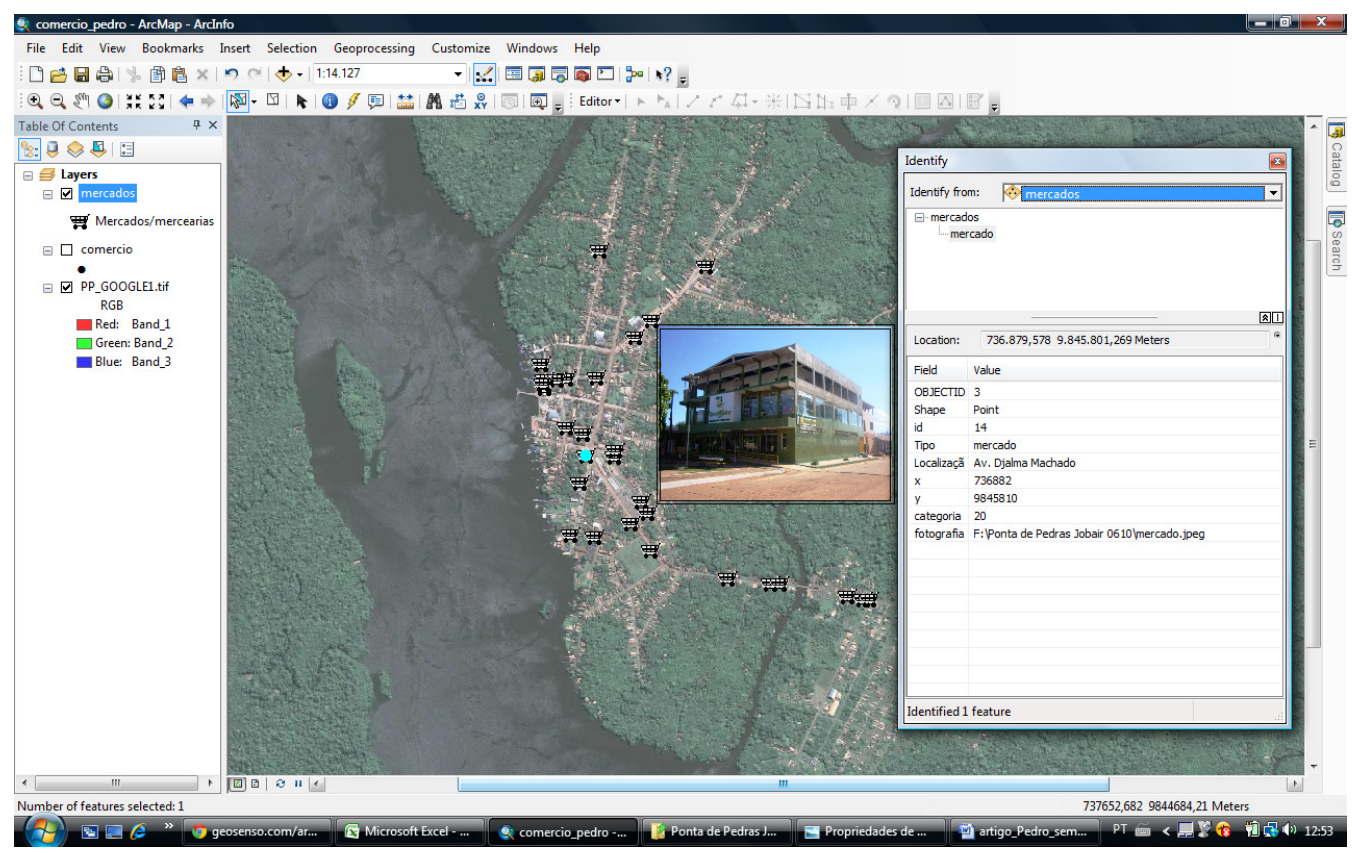

Fig. 3 - Exemplo de consulta ao banco de dados do ArcMap ${ }^{\mathrm{TM}}$, ressaltando a fotografia do estabelecimento selecionado na consulta (ponto azul).

Tabela 1 - Frequência dos Tipos de Estabelecimentos Comerciais Mapeados

\begin{tabular}{lc}
\hline \multicolumn{1}{c}{ Tipologia } & Frequência \\
\hline academia & 1 \\
celular & 1 \\
funerária & 1 \\
lava rápido & 1 \\
locadora & 1 \\
marcenaria & 1 \\
mecânica motos & 1 \\
mercado municipal & 1 \\
oficina & 1 \\
posto de combustivel & 1 \\
bebidas & 2 \\
borracharia & 2 \\
comercio de gás & 2 \\
ótica & 2 \\
restaurante & 2 \\
serralheria & 2 \\
TOTAL & 22 \\
\hline
\end{tabular}

\begin{tabular}{lc}
\hline \multicolumn{1}{c}{ Tipologia } & Frequência \\
\hline farmácia & 3 \\
ass. técnica & 4 \\
bicicletaria & 4 \\
lanchonete & 4 \\
xerox & 4 \\
lan house & 5 \\
salão cabelereiro & 5 \\
mecânica & 7 \\
mat. construção & 8 \\
açougue & 12 \\
bar & 18 \\
açai & 21 \\
mercado & 30 \\
mercearia & 32 \\
vestuário & 48 \\
TOTAL & 205 \\
\hline
\end{tabular}




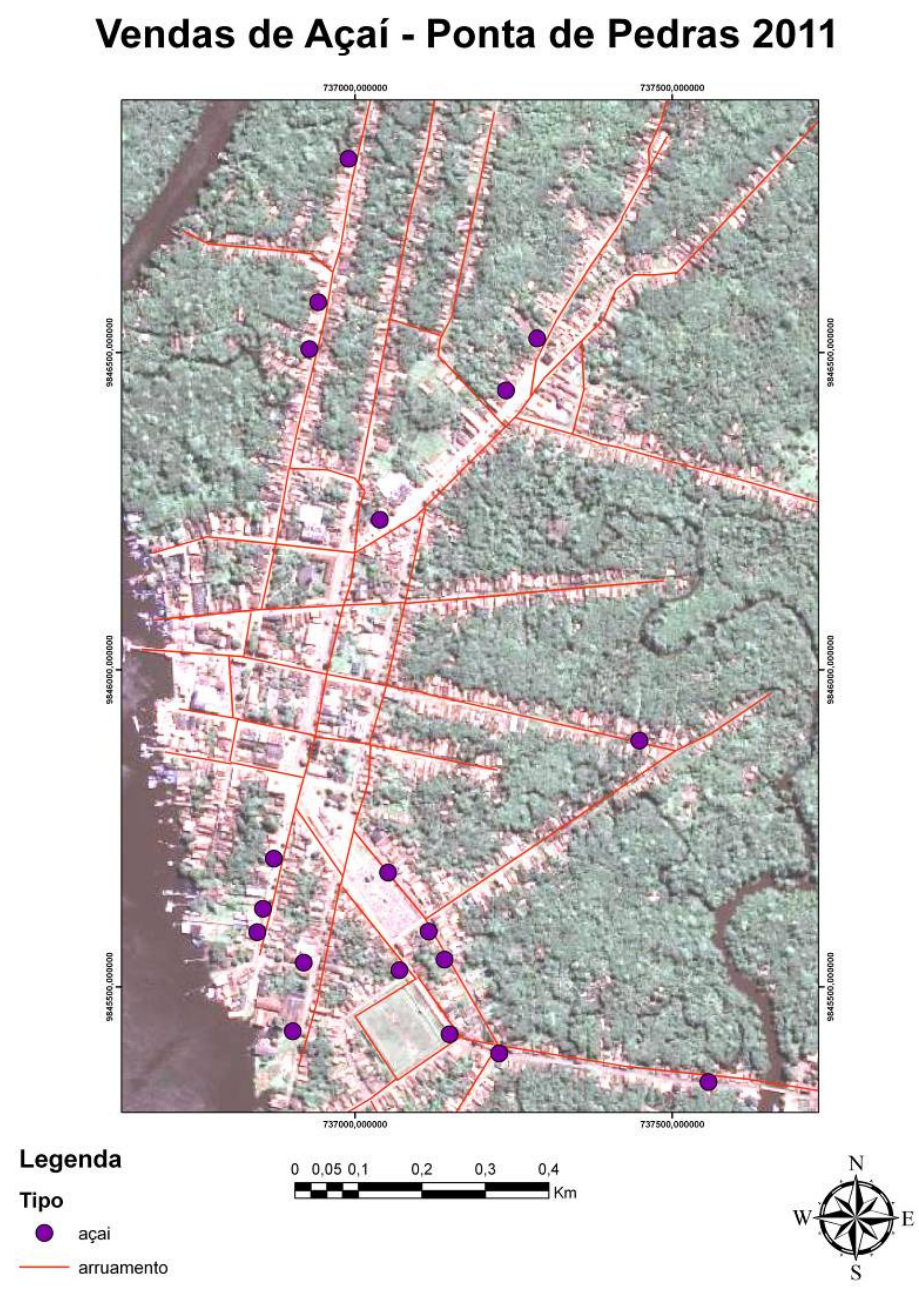

Fig. 4 - Mapa da localização dos estabelecimentos comerciais que vendem açaí Fonte: Elaboração dos autores, baseando-se em dados de trabalho de campo.

$\mathrm{Na}$ Fig. 5a, estão representadas as mercearias, que são estabelecimentos de menor porte e menor qualidade de infraestrutura, comparando-se com os mercados (Fig. 5b), que são maiores e disponibilizam uma variedade maior de produtos ao consumidor local. De acordo com essas Figs., $5 a$ e 5b, é possível observar que há diferença em relação à localização dos tipos de comércio. A Fig. 5a apresenta a distribuição das mercearias, que são estabelecimentos de tamanho pequeno ou de estrutura física precária, inseridas no contexto da cidade, incluindo as áreas mais distantes do Centro. De acordo com os dados coletados, $32 \%$ desses estabelecimentos localizam-se nos setores mais afastados do centro da cidade (em destaque, elipse na cor preta), onde as residências de palafitas predominam, e a infraestrutura básica é precária. Ressalta-se, também, que as mercearias, por existirem em todos os setores, atendem à população no que diz respeito ao consumo de "miudezas" diárias. 


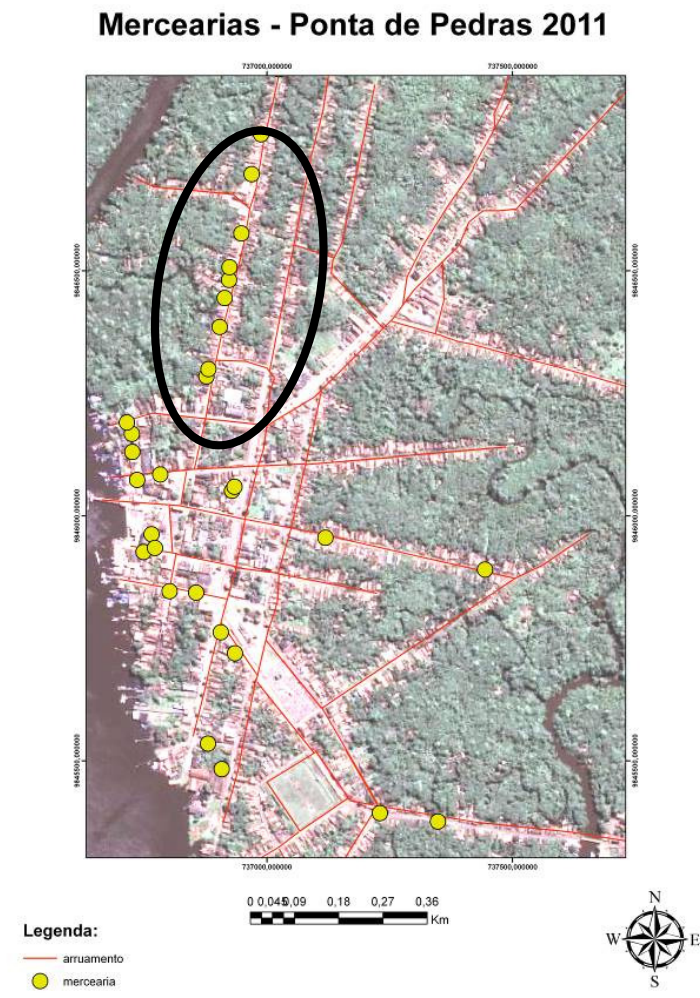

(a)
Mercados - Ponta de Pedras 2011
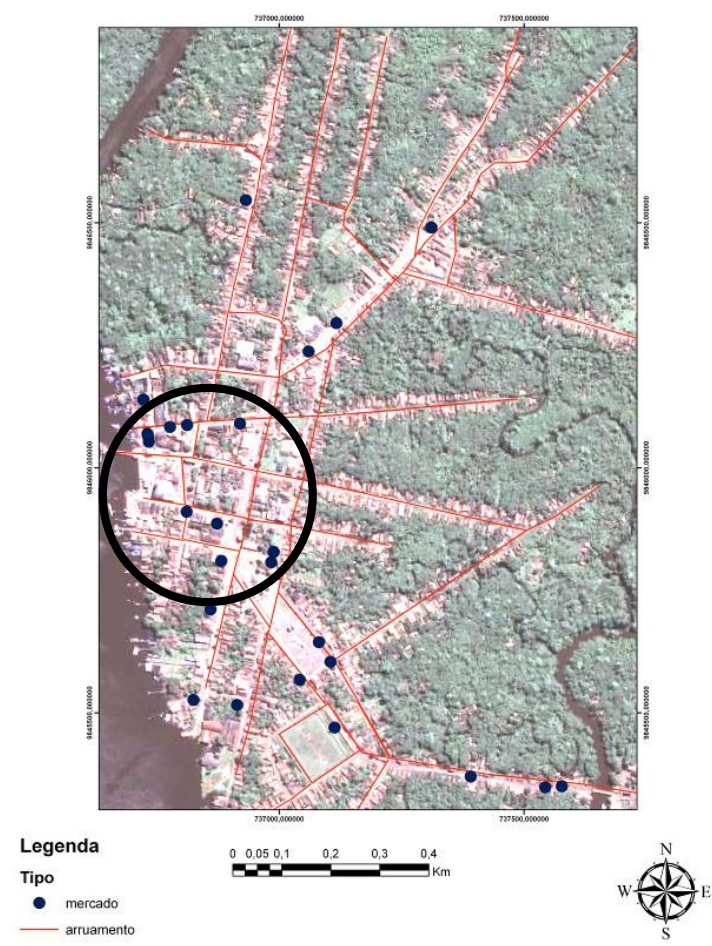

(b)

Fig. 5 - (a) Mapa da localização das mercearias, (b) mapa da localização dos mercado. Fonte: Elaboração dos autores, baseando-se em dados de trabalho de campo.

$\mathrm{Na}$ Fig. 5b, observa-se que há uma concentração de mercados no centro (círculo na cor preta) e uma melhor distribuição ao sul do mapa. No caso em questão, os mercados, estabelecimentos que necessitam de uma estrutura física mais adequada ao comércio de grande porte, em relação às mercearias. Dessa forma, $45 \%$ desses estabelecimentos encontram-se no centro da cidade, onde se observa melhor acessibilidade a esses estabelecimentos, em função da existência de vias pavimentadas. A partir da Fig. 6, elaborada utilizando-se a função de densidade de pontos, disponível no ArcMap $^{\mathrm{TM}}$, pode-se observar a presença de manchas maiores e com uma maior intensidade de cor, indicando que, na área central, há uma densidade maior de estabelecimentos comerciais do que em outras áreas da cidade.

$\mathrm{Na}$ Fig. 7a, é possível perceber a precariedade das residências da cidade de Ponta de Pedras, formadas, predominantemente, por construções de madeira sobre estacas, também de madeira, conhecidas como palafitas, indicativo das baixas condições de vida da população, em áreas sujeitas à inundação. O comércio, localizado em residências, como a demonstrada na Fig. 7a, acompanha o mesmo padrão de construção, ou seja, construções precárias e produtos mal condicionados, o que não deveria ocorrer, considerando que se trata de alimentos. Esses estabelecimentos comerciais são utilizados, inicialmente, para abastecer os 
moradores dos arredores, movimentando uma pequena economia em torno dessas relações de compra e venda. Na Fig. 7b, pode-se observar o maior mercado existente na cidade, o qual possui a melhor infraestrutura do ramo e oferece uma variedade de produtos.
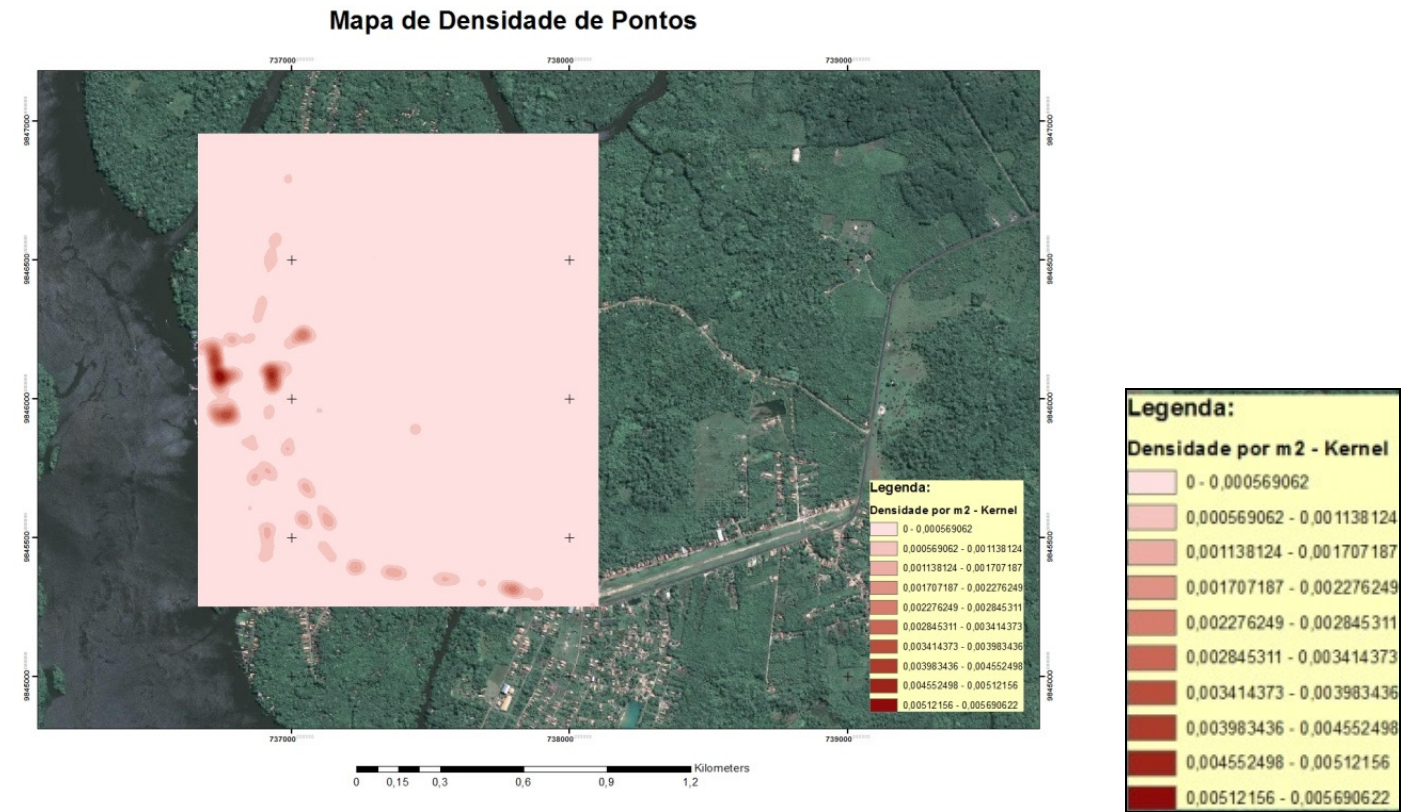

Fig. 6 - Mapa de densidade de pontos, considerando os estabelecimentos comerciais mapeados.

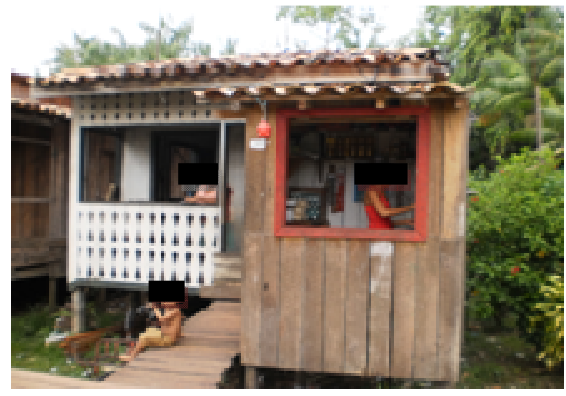

(a)

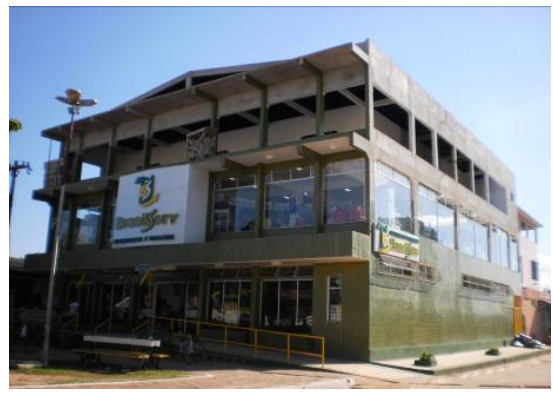

(b)

Fig. 7 - Imagem de mercados: (a) comércio localizado dentro de uma residência; e (b) comércio de grande porte, localizado na área central da cidade. Fonte: Obtida pelos autores, em julho de 2011.

Durante 0 trabalho de campo, infraestrutura, porém descentraliza o realizado em julho de 2011, constatou-se comércio. É importante citar que, de acordo que a presença desses estabelecimentos com entrevistas informais, realizadas com não significa melhorias em termos de comerciantes, mesmo estando em um bairro 
afastado do centro, muitos desses pequenos comerciantes não residem nesses locais, entretanto, optam por abrir o comércio, pois percebem um potencial econômico na atividade comercial.

No gráfico da Fig. 8, observa-se o número dos estabelecimentos comerciais das principais categorias. Por meio dessas informações, é possível perceber qual atividade econômica predomina e, dessa forma, definir o crescimento do comércio por ramo de atividade. No gráfico, os dados em linha representam a porcentagem dos estabelecimentos (eixo vertical esquerdo) e em barra, o número total dos establecimentos mapeados (eixo vertical direito).

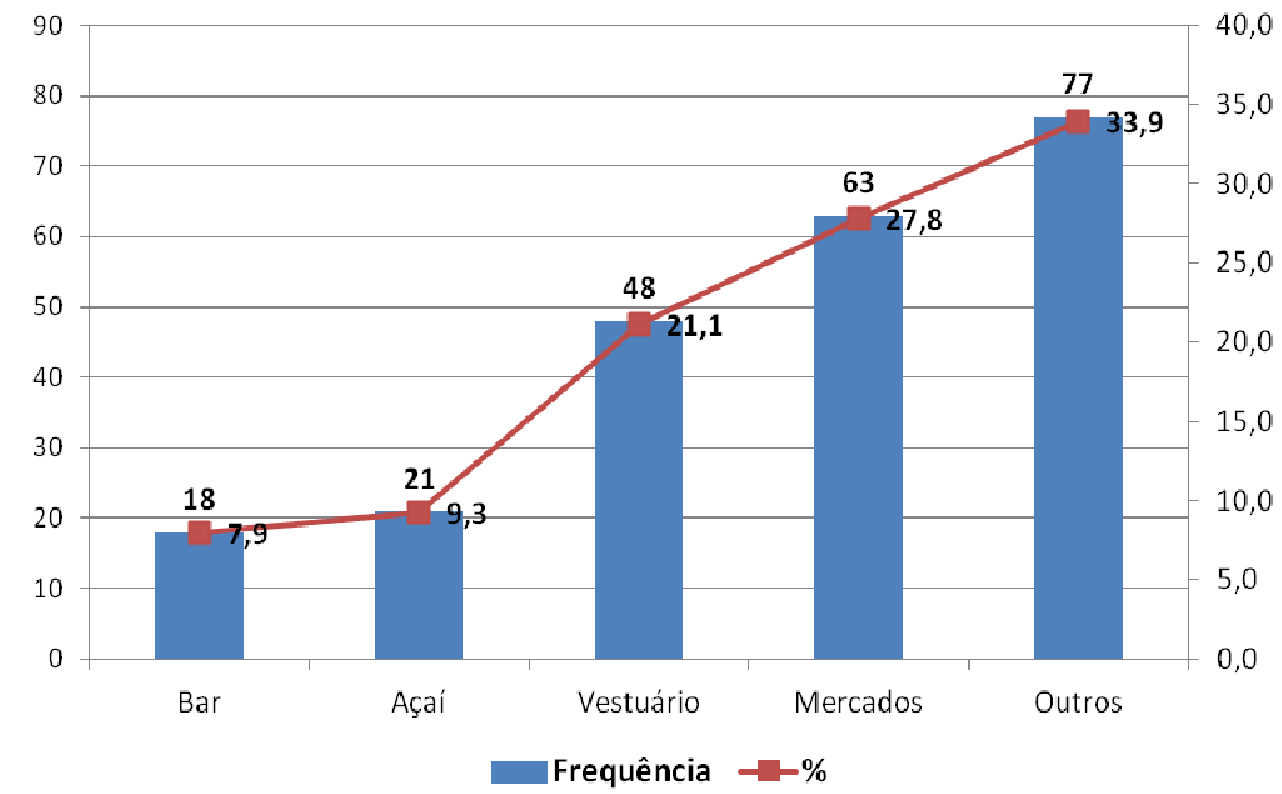

Fig. 8 - Número total e percentagem dos estabelecimentos comerciais da cidade de Ponta de Pedras

De acordo com os dados levantados, há uma concentração de estabelecimentos comerciais voltados à comercialização de alimentos (mercados e mercearias), representando $27,9 \%$ do total observado. 0 setor de vestuário aparece em segundo lugar, com $21 \%$ dos estabelecimentos, e o comércio de açaí (venda de polpa), representa o terceiro maior conjunto de estabelecimentos comerciais (9,3\%). $\mathrm{Na}$ categoria "outros", foram incluídas tipologias variadas de estabelecimentos, com número total menor que 12 (doze), as quais estão detalhadas na Tabela 1.

Considerando os setores censitários, no gráfico da Fig. 9, é possível notar a concentração dos estabelecimentos comerciais nos setores 1 e 2 (63,9\%), que se localizam no centro da cidade, como foi demonstrado na Fig. 6. Esse resultado era esperado, considerando que essa área é a mais antiga e, consequentemente, a mais consolidada e com melhores condições de acessibilidade, de forma que o estabelecimento de atividades vinculadas ao 
setor de serviço é favorecido. Os setores 21 e 22 congregam $23 \%$ dos estabelecimentos comerciais, pois, embora estejam localizados a uma distância maior do centro da cidade, existem conjuntos habitacionais que concentram população, como, por exemplo, o conjunto habitacional Nella Ramella, propiciando o aparecimento desse tipo de comércio. Esses setores foram ocupados após o ano de 2000, e possuem pouca infraestrutura $(0 \%$ de domicílios conectados à rede de água e esgoto), apresentando comércios com infraestrutura muito precária, tais como ruas sem pavimentação e esgoto a céu aberto.

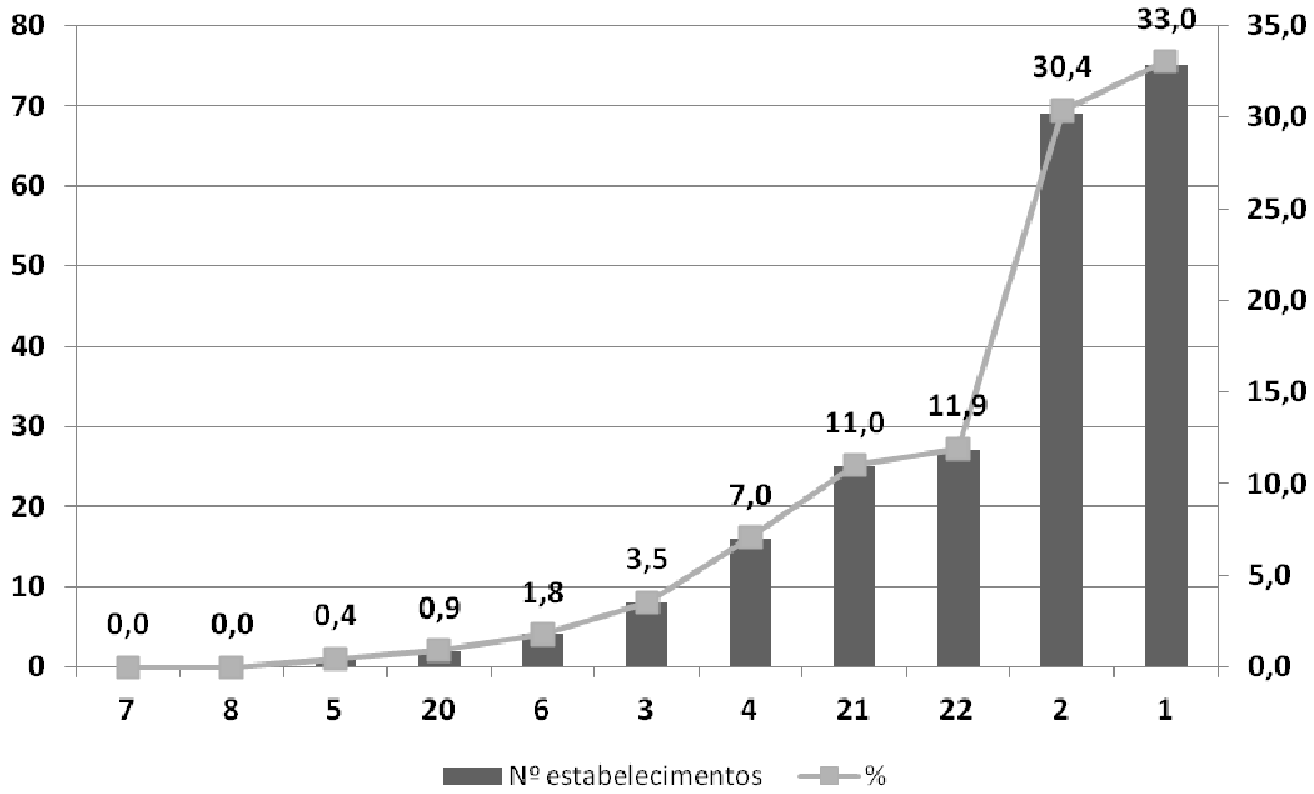

Fig. 9 - Estabelecimentos comerciais por setor censitário, em números absolutos e porcentagem.

No centro da cidade, são encontrados diversos tipos de estabelecimentos comerciais, e de portes variados, porém o fato mais interessante é a presença de mercados de maior porte, como o apresentado na Fig. 7b. O número de estabelecimentos dessa categoria na cidade cresceu, significativamente, depois de 2005. Em 2007, existia apenas um mercado que podia ser considerado de grande porte. Em 2011, foram mapeados quatro estabelecimentos.

Diferentes consumidores estão presentes na cidade, sendo que a maioria da população urbana possui baixo poder aquisitivo ${ }^{1}$. Entretanto, como consumidores, e dadas as dificuldades de deslocamento para o centro regional, a cidade de Belém, essa parcela da população de Ponta de Pedras adquire os produtos de primeira necessidade na própria cidade. Desta forma, a instalação de um comércio de grande porte na cidade facilita e atende à demanda dessa parcela da população local, bem como dos moradores das comunidades ribeirinhas que, também, enfrentam dificuldades para se deslocar para a capital.

\footnotetext{
1 A média salarial da população urbana era, em 2010, de acordo com Costa (2011), de um salário mínimo e meio.
} 
Em relação ao açaí, o qual é a identidade econômica e cultural da região, sua presença comercial é significativa, tanto informal como formalmente, com predomínio do informal. O comércio do açaí está presente em todos os bairros da cidade e representa quase $10 \%$ do total desses estabelecimentos.

A instalação dos estabelecimentos comerciais, principalmente os distantes do centro, ocorre sem o devido planejamento e isso pode trazer inúmeros ônus para a sociedade, principalmente no que diz respeito à evasão de receita fiscal, pela grande informalidade existente. De acordo com dados da Prefeitura Municipal de Ponta de Pedras, obtidos em 2011, apenas quarenta e seis estabelecimentos pagavam imposto à Prefeitura, o que comprova a necessidade de estabelecer um monitoramento mais adequado, em relação ao comércio.

\section{CONSIDERAÇÕES FINAIS}

Como já mencionado, esta pesquisa teve como objetivo apresentar uma aplicação da utilização de um SIG, na elaboração de um mapeamento de estabelecimentos comerciais urbanos, de um município pequeno da Amazônia. O mapeamento realizado, e o acompanhamento da expansão comercial são importantes informações para o poder público. No caso desta pesquisa, esse mapeamento foi facilitado pela utilização de dados coletados em campo (pontos GPS), permitindo gerar 0 cadastro dos estabelecimentos comerciais da cidade.

O mapeamento realizado, apesar de sua simplicidade de resultados, possibilitou criar um banco de dados, que pode ser atualizado periodicamente, permitindo a inclusão de mais informações sobre os estabelecimentos. Dados sobre a situação fiscal, data do início das atividades, área construída e área do terreno ocupado, nome do proprietário, número de funcionários, entre outras informações, podem auxiliar no processo de monitoramento desses estabelecimentos, por parte do poder público, assim como, no processo de abertura de novos estabelecimentos, em função da capacidade de suporte do setor.

O ArcMap ${ }^{\mathrm{TM}}$, o SIG utilizado para o processamento dos dados, mostrou-se eficiente, apesar de não terem sido utilizadas ferramentas mais sofisticadas, que poderiam fornecer outras informações e possibilidades de análise, tais como análise de correlação espacial, para verificar se existem agrupamentos dos estabelecimentos e os diferentes tipos de comércio levantados. Outra possibilidade seria correlacionar a área de abrangência dos estabelecimentos, com a população residente, por meio de uma análise de proximidade. Entretanto, essas análises estão previstas para a pesquisa em curso, a qual se relaciona este artigo.

Foi possível perceber, também, por meio dos mapas e gráficos apresentados, que a cidade de Ponta de Pedras possui uma grande diversidade de estabelecimentos comerciais, sendo que muitos deles podem ser considerados informais, ao confrontá-los com a base de dados da Prefeitura. Nesse aspecto, o mapeamento torna-se mais fundamental para possibilitar compreender a dimensão dessa informalidade, em uma segunda etapa da pesquisa. 
Ressalta-se que os sistemas de informação geográfica, devido à sua capacidade de integrar dados de diferentes fontes e datas de aquisição, podem propiciar o conhecimento atualizado e efetivo do espaço geográfico, para que sejam tomadas decisões adequadas sobre problemas existentes ou potenciais, subsidiando, assim, o planejamento municipal. As informações apresentadas neste artigo possibilitam fornecer, além de análises mais complexas, em relação à distribuição dos estabelecimentos comerciais no espaço geográfico de Ponta de Pedras, subsídios importantes para o planejamento e gestão do município.

\section{REFERÊNCIAS}

BRONDÍZIO, E. S. The Amazonian Caboclo and the Açaí palm: Forest Farmers in the Global Market. New York: New Botanical Garden Press, 2008. 403p.

BURROUGH, P. A. Principles of geographical information systems. Oxford: University Press, 1998. 356 p.

CÂMARA, G.; MEDEIROS, J. S. de. Geoprocessamento para projetos ambientais. São José dos Campos: Instituto Nacional de Pesquisas Espaciais, 1996. Disponível em:

http://www.dpi.inpe.br/gilberto/tutoriais/gis_a mbiente. Acesso em 24 set 2011.

CÂMARA, G. Princípios Básicos em Geoprocessamento. In: ASSAD, E. D.; SANO, E. E. Sistema de Informações Geográficas: Aplicações na Agricultura. 2. ed. Brasília: Embrapa, 1998. p. 3-11.

COSTA, S. M. F.; BRONDIZIO, E.; MONTOIA, G. As Cidades Pequenas do Estuário do Rio Amazonas: Crescimento
Urbano e Rede Sociais da cidade de Ponta de Pedras, PA. In: XI SIMPÓSIO NACIONAL DE GEOGRAFIA URBANA. SIMPURB: 20 anos de reflexões sobre o urbano e a cidade, 11., 2009, Brasília. Anais... Brasília: UnB, 2009. v. 1. p. 1-20.

COSTA, S.; BRONDÍZIO, E. Floodplain Cities of the Brazilian Amazon: Characteristics and Trends. In: PINEDOVASQUEZ, M. et al. (eds). The Amazon Várzea: the decade past and the decade ahead. New York: Spring-Verlag Press; The New York Botanical Garden Press, 2011. $362 \mathrm{p}$.

COSTA, S. et al. Urban Growth and Social Network of Small Cities of the estuarine region of Amazon River: The Case of the City of Ponta de Pedras, Pará State, Brazil. In: ANNUAL RC21 CONFERENCE: Sociology of Urban and Regional Development. 21., 2011, Amsterdam. Proceedings...: The struggle to belong. Dealing with diversity in 21st century urban settings. Amsterdam: University of Amsterdam, 2011. p. 1-20.

DI MAIO, A. C. Introdução à Cartografia. In: GEODEM: Geotecnologias Digitais no Ensino Médio, módulo I. Disponível em: <http://www.uff.br/geoden/index_intro_cartogr afia_geodem.htm>. Acesso em: 12 dez. 2011.

INSTITUTO BRASILEIRO DE PESQUISA E ESTATÍSTICA. Censo 2010, 2011. Disponível em: <http://www.ibge.gov.br>. Acesso em: 24 set. 2011.

INSTITUTO NACIONAL DE PESQUISAS ESPACIAIS. Projeto Prodes. Disponível em $<$ http://www.obt.inpe.br/prodes>. Acesso em: 09 dez. 2011.

TEIXEIRA, M.; KARSBURG, R. Cadastro Técnico Multifinalitário. Florianópolis: UFSC, 2011. (Apostila). 